\title{
Yapay Sinir Ağları Kullanılarak Orta Dönem Elektrik Enerjisi Tüketim Tahmini: İskenderun Örneği
}

\author{
Merve Erkınay Özdemir \\ İskenderun Teknik Üniversitesi, Mühendislik ve Doğa Bilimleri Fakültesi, Elektrik Elektronik Mühendisliği Bölümü, İskenderun, Türkiye, (ORCID: 0000-0001-8864-
} 385X), merve.erkinayozdemir@iste.edu.tr

(1st International Conference on Applied Engineering and Natural Sciences ICAENS 2021, November 1-3, 2021)

(DOI: 10.31590/ejosat.1007589)

ATIF/REFERENCE: Özdemir Erkınay, M. (2021). Yapay Sinir Ağları Kullanılarak Orta Dönem Elektrik Enerjisi Tüketim Tahmini: İskenderun Örneği. European Journal of Science and Technology, (28), 489-492.

Öz

Akıllı şebeke sistemlerinin son zamanlarda elektrik güç sistemlerinde kullanılması, güç sistemlerinin çalışması ve sürdürebilmesi, yenilenebilir enerji kaynaklarının kullanımının artması elektrik enerjisi tüketimi tahminini oldukça önemli bir hale getirmiştir. Enerji tüketimini etkileyen doğrusal ve durağan olmayan özellikler enerji tüketim tahminini zorlaştırmaktadır. Orta dönem elektrik enerjisi tüketimi tahminleri 2 haftadan 3 yıla kadar olan tahminleri içermektedir ve güç sistemlerinin verimli çalışması, enerji ihtiyaçlarının doğru belirlenerek gerekli önlemlerin alınması ve bu alanda çalışan şirketlerin ihtiyaçlarının belirlenmesi açısından oldukça önemlidir. Bu çalışmada yapay sinir ağları kullanılarak İskenderun için orta dönem elektrik enerjisi tüketim tahmini yapılmıştır. Elde edilen sonuçlar geliştirilen yapar sinir ağının İskenderun orta dönem elektrik enerjisi tüketim tahmini için kullanılabileceğini ve bu modelin tahmin performansının yüksek olduğunu göstermiştir. Sonuçlar geliştirilen yapay sinir ağının yenilenebilir enerji teknolojileriyle ilgili yatırım yapan, faaliyet gösteren şirketler ve büyük devlet tesislerinin bu alandaki ihtiyaçlarını karşılayabileceğini göstermektedir.

Anahtar Kelimeler: Orta dönem, Elektrik enerjisi, Tüketim, Tahmin, Yapay sinir ağları.

\section{Mid-Term Electrical Energy Consumption Forecasting Using Artificial Neural Networks: A case study for İskenderun}

\begin{abstract}
Absract
The use of smart grid systems in electrical power systems, the operation and maintenance of power systems, and the increase in the use of renewable energy sources have made the estimation of electrical energy consumption very important. Linear and non-stationary features affecting energy consumption make energy consumption estimation difficult. Mid-term electrical energy consumption forecasting include forecastings from 2 weeks to 3 years and the efficient operation of power systems is very important in terms of determining the energy needs correctly and taking the necessary precautions and determining the needs of the companies working in this field. In this study, mid-term electrical energy consumption forecasting was made for İskenderun using artificial neural networks. The results showed that the developed artificial neural network can be used for mid-term electrical energy consumption forecasting for Iskenderun and the forecasting performance of this model is high. The results showed that the developed artificial neural network can provide the needs of companies and big government facilities that invest in renewable energy technologies and operate in this field.
\end{abstract}

Anahtar Kelimeler: Mid-term, Electrical energy, Consumption, Forecasting, Artificial neural networks. 


\section{Giriş}

Akıllı bilgi ve iletişim teknolojileri, mevcut ve gelecekteki küresel enerji sorunlarının ele alınması açısından oldukça önemli bir role sahiptir. Dünyanın başlıca enerji kaynakları petrol, doğal gaz, kömür, elektrik ve yenilenebilir enerji kaynaklarıdır. Son yıllarda, ekonomik ve nüfus artışı nedeniyle her bir enerji kaynağının tüketiminin çarpıcı biçimde arttığı açıktır. Enerji kaynaklarının büyük ölçekli tüketimi, yalnızca ekonomik ve nüfusun hızlı büyümesini yansıtmakla kalmamakta, aynı zamanda çevre kirliliğine de katkıda bulunmaktadır [1]. Çevre kirliliğini önleme ve enerji verimliliğini arttırma girişimlerinin başarılı bir şekilde uygulanması, enerji tüketim verilerinin tanımlayan ve doğru enerji tüketimi tahmini yapan etkili bir enerji yönetimi ile sağlanabilir. Enerji tüketimi tahmini enerji yönetiminin temelini oluşturmaktadır.

Yenilenebilir enerji teknolojilerinin günümüz enerji santralleri arasında artan payı ve akıllı şebeke sistemlerinin günümüzün elektrik güç sistemlerine mevcut entegrasyonu, enerji tahminini sadece enerji alanında popüler bir konu haline getirmekle kalmamakta, aynı zamanda sosyal aktiviteler, iklim ve mevsimsel faktörler gibi öngürüsü zor olan ve tahmini etkileyen faktörler nedeniyle oldukça zorlu ve önemli bir süreç olarak karşımıza çıkmaktadır.

Enerji tüketim tahmini, tahmin yapılan zaman periyoduna göre sınıflandırılmaktadır. Ultra kısa dönem elektrik enerjisi tüketimi tahmini 1 dakika ile 1 saat arası tahminleri, kısa dönem elektrik enerjisi tüketimi tahmini ise 1 saat ile 2 hafta arası tahminleri içerir. Orta dönem elektrik enerjisi tüketimi tahmini, 2 haftadan 3 yıla kadar tahminleri ve uzun vadeli elektrik enerjisi tahmini 3 yıldan 50 yıla kadar olan tahminleri içerir [2].

Uzun dönem elektrik enerjisi tüketim tahmini, bir ülkenin gelecekteki enerji talebi ve enerji politikasına uygun olarak uzun vadeli güç sistemi planlaması için kullanılmaktadır [3]. Orta dönem elektrik enerjisi tahmini, güç sistemindeki büyük tesislerin verimli çalışması ve bakımı için kullanılmaktadır [4]. Aynı zamanda, piyasadaki enerji ihtiyacı, bakım programı, yakıt tedariği ve yenilenebilir enerji teknolojileriyle ilgili yatırım için ihtiyaçlar hakkında değerli bilgiler sağlamasından dolayı, bu alanda faaliyet gösteren şirketler ve büyük devlet tesisleri tarafindan kullanılmaktadır $[5,6]$. Ultra kısa dönem ve kısa dönem elektrik enerjisi tahmini optimum birim taahhüdü, rezervlerin kontrolü ve birkaç şirket arasındaki satış veya satın alma sözleşmelerinin değerlendirilmesinde çok önemli bir rol oynamaktadır $[7,8]$.

Enerji tüketimi tahmini için yapılan çalışmalar, genel olarak istatistiksel modeller ve yapay zeka tabanlı modeller olarak sınıflandırılabilir [9]. Yapay zeka teknolojisinin yükselişinden önce, enerji tüketimi tahmini için literatürde temel olarak zaman serisi modelleri ve regresyon modelleri gibi yöntemler kullanılmıştır [10,11]. Olağan günlük koşullar altında, istatistiksel tekniklerin iyi performansları vardır, ancak zamanla güncellenemezler, bu nedenle klimatolojik, ekonomik veya sosyolojik farklılıklar nedeniyle tatmin edici sonuçlar veremezler. Günümüzde yapay sinir ağları, destek vektör makinası, genetik algoritma gibi yöntemler doğrusal olmayan problemleri çözme konusunda güçlü bir yeteneğe sahip oldukları ve tahmin hatalarını azalttıkları için enerji tüketimi tahmininde yaygın olarak kullanılmaktır [12, 13, 14].
Bu çalışmada yapay sinir ağları kullanarak İskenderun için aylık enerji tüketim tahmini yapılmıştır. Giriş bölümünden sonra materyal ve yöntem bölümünde çalışmada kullanılan veri seti, yapay sinir ağları ve sonuçları değerlendirme yöntemleri anlatılmıştır. Çalışmanın önemli sonuçları ve sonuçların değerlendirilmesi bulgular ve tartışma bölümünde verilmiştir. Son olarak çalışmanın ana sonuçları sonuç bölümünde özetlenmiştir.

\section{Metaryal ve Yöntem}

$\mathrm{Bu}$ bölümde İskenderun için aylık elektrik enerjisi tahmininde kullanılan veri seti, yapay sinir ağları ve sonuçları değerlendirmek için kullanılan ortalama mutlak yüzde hata (Mean Absolute Percentage Error-MAPE) yöntemi anlatılmıştır

\subsection{Veri Seti}

Bu çalışmada aylık enerji tüketimi tahmini için 2011-2020 yılları arasında aylık ortalama sicaklık ve aylık ortalama enerji tüketimi verileri kullanılmıştır. Yıllara göre aylık ortalama sıcaklık değerleri değişimi ve aylık ortalama enerji tüketim değerleri değişimi Tablo 1'de verilmiştir.

Tablo 1. 2011-2020 yılları aylık ortalama sicaklık değerleri değişimi ve aylık ortalama enerji tüketim değerleri değişimi

\begin{tabular}{|l|l|l|}
\hline Aylar & $\begin{array}{l}\text { Ortalama Sıcaklık } \\
\text { Değişimi }\end{array}$ & $\begin{array}{l}\text { Ortalama Enerji } \\
\text { Tüketimi Değişimi }\end{array}$ \\
\hline Ocak & $9^{\circ}-13^{\circ}$ & $43 \mathrm{MW}-189.1 \mathrm{MW}$ \\
\hline Şubat & $12^{\circ}-15^{\circ}$ & $38 \mathrm{MW}-188 \mathrm{MW}$ \\
\hline Mart & $15^{\circ}-20^{\circ}$ & $38.5 \mathrm{MW}-186.6 \mathrm{MW}$ \\
\hline Nisan & $17^{\circ}-23^{\circ}$ & $33.1 \mathrm{MW}-151.1 \mathrm{MW}$ \\
\hline Mayıs & $21^{\circ}-25^{\circ}$ & $27.4 \mathrm{MW}-165.8 \mathrm{MW}$ \\
\hline Haziran & $23^{\circ}-26^{\circ}$ & $29.5 \mathrm{MW}-181.9 \mathrm{MW}$ \\
\hline Temmuz & $25^{\circ}-36^{\circ}$ & $38.4 \mathrm{MW}-189 \mathrm{MW}$ \\
\hline Ăgustos & $26^{\circ}-28^{\circ}$ & $38.2 \mathrm{MW}-188.5 \mathrm{MW}$ \\
\hline Eylül & $25^{\circ}-28^{\circ}$ & $29.3 \mathrm{MW}-161.6 \mathrm{MW}$ \\
\hline Ekim & $21^{\circ}-25^{\circ}$ & $29.2 \mathrm{MW}-153.3 \mathrm{MW}$ \\
\hline Kasım & $15^{\circ}-20^{\circ}$ & $36.5 \mathrm{MW}-176.3 \mathrm{MW}$ \\
\hline Aralık & $12^{\circ}-15^{\circ}$ & $44.4 \mathrm{MW}-185 \mathrm{MW}$ \\
\hline
\end{tabular}

Çalışmada yapılan aylık elektrik enerjisi tüketim tahmini için geliştirilen yapay sinir ağlarının (YSA) giriş ve çıkışı için kullanılan veriler Şekil 1'de gösterilmiştir.

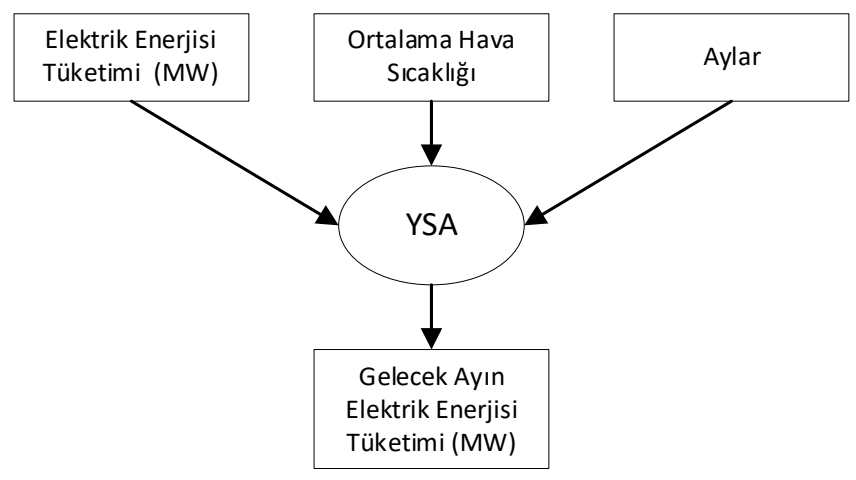

Şekil 1 Giriş ve çıkış verilerinin akış şeması 


\subsection{Yapay Sinir A ğları}

Yapay sinir ağları (YSA) örüntü tanıma, tanımlama, sınıflandırma, konuşma, görme ve kontrol sistemleri gibi birçok farklı uygulamada karmaşık problemleri çözmek için başarıyla kullanılan akıllı sistemlerdir [15]. YSA yapısı, insan beyninin biyolojik sinir sistemi anlayışına dayanmaktadır. YSA'lar, girdi ve çıktı uzayları arasındaki ilişkinin dinamikleri hakkında bilgi sahibi olmadan çok boyutlu bir girdi uzayının başka çok boyutlu çıktı uzayına doğrusal olmayan haritalanmasını gerçekleştirebilen "kara kutu" modelleme tekniğidir [16]. YSA'nın en basit ve en küçük birimi olan nöronlar, nöronlar ve ağırlık parametreleri arasındaki karmaşık davranışları yönetme yeteneğine sahiptir.

YSA modelleri temel olarak birbirlerine bağlı nöronlar ve düğümlerden oluşur. Yapay nöronlar, Şekil 2'de gösterildiği gibi giriş, ağırlık, eşik değeri, toplama fonksiyonu, aktivasyon fonksiyonu ve çıkış olmak üzere temel bileşenlere sahiptir.

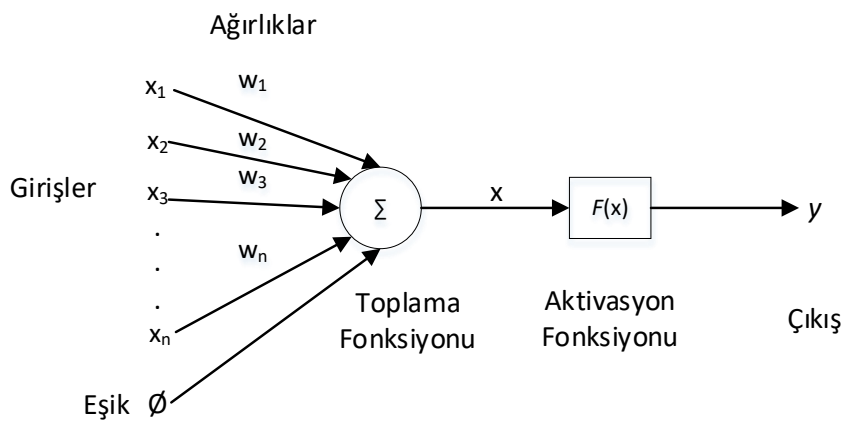

Şekil 2. Yapay nöronun yapısl

Genel olarak ileri beslemeli çok katmanlı YSA'nın temel topolojisi Şekilde 3'de gösterildiği gibi giriş katmanı, gizli katman ve çıkış katmanı olacak şekildedir.

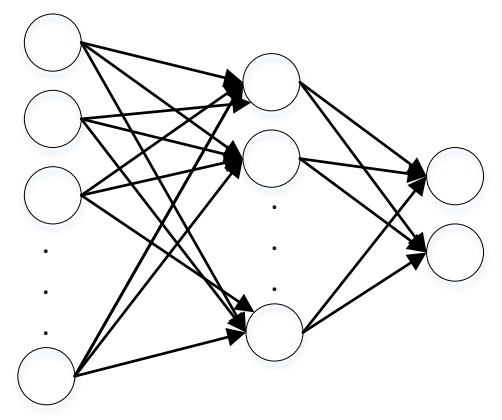

Giriş Katmanı Gizli Katman Çıkış Katmanı

Şekil 3. Çok katmanll ileri beslemeli yapay sinir ă̆l modeli

Temel bir YSA modelinde $x_{k}$ girdisi bir ağırlıkla çarpılır ve bir eşik değeri eklenir. $\mathrm{n}$ adet giriş değeri için net giriş $u_{k}$ denklem 1 'de verildiği gibi hesaplanır;

$$
u_{k}=\sum_{k=1}^{n} w_{j k} x_{k}-\emptyset_{j}
$$

$y_{j}$ çıkışını elde etmek için $u_{k}$ lineer ya da lineer olmayan bir $f(x)$ transfer fonksiyonuna uygulanır. Ağın çıkışı matematiksel olarak denklem 2'de verildiği gibi hesaplanır;

$$
y_{j}=f\left(\sum_{k=1}^{n} w_{j k} x_{k}-\emptyset_{j}\right)
$$

Denklem 2'de n giriş sayısını, $w_{j k}$, j. nörona karşılık gelen k. girişin ağırlık değerini, $\emptyset_{j}$ uygulanan eşik değerini göstermektedir.

Ç1kış $y_{j}$, denklem 3'de gösterilen hata fonksiyonu kullanılarak hedeflenen çıkış değeri $d_{j}$ ile karşılaştırılır;

$$
\delta_{j}=y_{j}\left(1-y_{j}\right)\left(d_{j}-y_{j}\right)
$$

YSA'nın eğitilmesi en önemli işlemlerden biridir. YSA'nın eğitilmesi uygun bir öğrenme yöntemi kullanılarak bağlantı ağırlıklarının belirli bir düzen içinde değiştirilmesi işlemi olarak açıklanabilir. Ağ, istenen çıtıyla birlikte bir girdinin ağa sunulduğu ve bu istenen çıktıyı üretmeye çalışacak şekilde ağırlıkların ayarlandığı bir öğrenme modu kullanır. Ağırlıklar ağ eğitilmeden önce rastgeledir ve herhangi bir anlam içermezler, ancak eğitimden sonra anlamlı bilgiler içerirler.

Eğitim için en çok kullanılan algoritmalardan biri geri yayılım algoritmasıdır. Bu algoritmada girişler ve elde edilmesi istenen çıkışlar ağa uygulanır ve çıkış elde edilir. Daha sonra ağın çıkışları ve istenen çıkışlar karşılaştırılarak hata bulunur. Bu işlem eğitim setindeki tüm verilere uygulanır ve epoch adı verilen bu eğitim döngüsü hata kabul edilebilir bir değere düşene kadar tekrarlanır [17]. Toplam hatayı azaltmak için; giriş katmanı, gizli katmanlar ve çıkış katmanı arasındaki ağırlıklar güncellenebilir Hata denklem 4'de verildiği gibi çıkış katmanından giriş katmanına yani geriye doğru yayılır.

$w_{j k}(t+1)=w_{j k}(t)+\eta \delta_{j} y_{j} \alpha\left(w_{j k}(t)-w_{j k}(t-1)\right)$

$\mathrm{Bu}$ çalışmada geliştirilen YSA için çok katmanlı ileri beslemeli YSA modeli kullanılmıştır. Eğitim için geri yayılım algoritmalarından Levenberg -Marquardt (LM) algoritması kullanılmış olup, tanjant sigmoid (tansig) transfer fonksiyonu kullanılmıştır. Geliştirilen YSA modelinin doğruluğu, gizli katmandaki nöron sayısına, gizli katman sayısına, giriş kombinasyonlarına ve öğrenme algoritmasına bağlıdır.

YSA için veri tabanında bulunan 120 adet verinin \%70'i eğitim \%30'u test için kullanılmıştır. Test için seçilen 2019 ve 2020 yıllarının aylarına göre ortalama elektrik enerjisi tüketim tahmini yapılmıştır. Test için kullanılan verilerin hiç biri YSA'nın eğitimi için kullanılmamıştır.

Bu çalışmada kullanılan çok katmanlı ileri beslemeli yapay sinir ağı modelinde başlangıçta YSA'da kaç adet gizli katman olacağını ve her gizli katmanda kaç adet nöron olacağını belirlemek mümkün değildir. Gizli katman sayısı ve nöron sayısı deneme yanılma yolu ile belirlenir. Bu çalışmada gizli katman ve nöron sayısı yapılan denemelerden sonra en iyi sonuç alınacak şekilde belirlenmiştir. Bu sonuca göre 3 adet gizli katman kullanılmıș olup her gizli katmanda sırasıyla 15, 1618 adet nöron bulunmaktadır.

\subsection{Ağın Performans Değerlendirme Kriteri}

Ağın performansını değerlendirmek ve hatayı belirtmek için istatistiksel hata tahmin yöntemleri kullanılmaktadır. Bu çalışmada geliştirilen YSA'nın sonuçlarını değerlendirmek için $M A P E$ (Mean Absolute Percentage Error- ortalama mutlak yüzde hata) değerleri kullanılmıştır. Bu değerler denklem 5'de verildiği gibi hesaplanmaktadır;

$$
\operatorname{MAPE}(\%)=\frac{\sum_{t=1}^{n}\left|\left(x_{t}-x_{t}^{\prime}\right) / x_{t}\right|}{n} \times 100
$$


Yukarıdaki denklemde $x_{t}$ çıkış değerini, $x_{t}{ }^{\prime}$ ise hedef çıkış değerini göstermektedir.

\section{Bulgular ve Tartışma}

Bu çalışmada geliştirilen YSA ile aylara göre enerji tüketimi tahmini için elde edilen ve yukarıda belirtildiği gibi hesaplanan MAPE değerleri Tablo 2'de gösterilmiştir.

Tablo 2. Uygulanan YSA'nın performansı

\begin{tabular}{|l|l|}
\hline Aylar & MAPE(\%) \\
\hline Ocak & 5,8 \\
\hline Şubat & 6,05 \\
\hline Mart & 2,95 \\
\hline Nisan & 4,24 \\
\hline Mayis & 5,21 \\
\hline Haziran & 1,62 \\
\hline Temmuz & 3,65 \\
\hline Ağustos & 8,69 \\
\hline Eylül & 3,06 \\
\hline Ekim & 5,1 \\
\hline Kasim & 5,8 \\
\hline Aralık & 6,05 \\
\hline
\end{tabular}

Tablo 2'deki sonuçlara göre MAPE değerleri bütün aylar için \%10 değerinden küçük elde edilmiştir. $\mathrm{Bu}$ sonuçlar geliştirilen YSA'nın tahmin performansının oldukça başarılı olduğunu göstermektedir.

Elde edilen sonuçlar geliştirilen YSA'nın İskenderun orta dönem elektrik enerjisi tüketim tahmini için uygulanabileceğini ve bu modelin çok iyi tahmin yapabildiğini göstermektedir. Bubölge için doğru bir şekilde yapılan orta dönem elektrik enerjisi tahmini, güç sistemindeki büyük tesislerin verimli çalışması ve bakımı için, piyasadaki enerji ihtiyacı, bakım programı, yakıt tedariği ve yenilenebilir enerji teknolojileriyle ilgili yatırım yapan ve bu alanda faaliyet gösteren şirketler ve büyük devlet tesislerinin bu alandaki ihtiyaçlarını karşılayabileceğini göstermektedir. Bu çalışma İskenderun bölgesi için bu alandaki eksikliği ve ihtiyacı karşılayan bir çalışma olmuştur.

\section{Sonuçlar}

Orta dönem elektrik enerjisi talebi tahmini günümüz güç sistemlerinin verimli çalışması, enerji ihtiyaçlarının doğru belirlenerek gerekli önlemlerin alınması ve bu alanda çalışan şirketlerin ihtiyaçlarının belirlenmesi açısından oldukça önem kazanmıştır. Bunun yanında elektrik enerjisi talebini etkileyen mevsimsel, sosyal ve iklimsel faktörlerden dolayı bu tahmini yapmak oldukça zordur.

Literatürde enerji tüketimi tahmini için genel olarak istatistiksel modeller ve yapay zeka tabanlı modeller kullanılmıştır. Yapılan çalışmalar yapay zeka tabanlı yöntemlerin doğrusal olmayan problemleri çözme konusunda güçlü bir yeteneğe sahip olduklarını ve tahmin hatalarını azalttıklarını göstermiştir.

$\mathrm{Bu}$ çalışmada İskenderun bölgesi için yapay sinir ağları kullanılarak ortan dönem elektrik enerjisi tüketim tahmini yapılmıştır. Bunun için çok katmanlı ileri beslemeli YSA modeli kullanılmıştır. Elde edilen sonuçlar geliştirilen YSA'nın elektrik enerjisi tahminini doğru ve başarılı bir şekilde yapabildiğini göstermiştir.

Bu çalışmada kullanılan yöntem geliştirilerek başka bölgeler için de uygulanabilir ve yenilenebilir enerji teknolojileriyle ilgili yatırım yapan, faaliyet gösteren şirketler ve büyük devlet tesislerinin bu konudaki ihtiyaçları giderilebilir.

\section{Kaynaklar}

[1] J. L. Harris, L.M. Liu, "Dynamic structural analysis and forecasting of residential electricity consumption," Int. J. Forecast, vol. 9, pp.437-455, 2007.

[2] T. Hong, S. Fan, "Probabilistic electric load forecasting: A tutorial review," Int. J. Forecast, vol.32, pp.914-938, 2016.

[3] A. Rahman, V. Srikumar, A.D. Smith. "Predicting electricity consumption for commercial and residential buildings using deep recurrent neural networks," Appl. Energy, vol.212, pp. 372-385, 2018

[4] Z. Yumurtaci, E. Asmaz, "Electric energy demand of Turkey for the year 2050," Energy Source, vol.26, pp.1157-1164, 2004.

[5] Z. Shao, F. Gao, Q. Zhang, S. Yang, "Multivariate statistical and similarity measure based semiparametric modeling of the probability distribution: a novel approach to the case study of mid-long term electricity consumption forecasting in China," Appl. Energy, vol.156, pp. 502-518, 2015.

[6] Z. Hu, Y. Bao, R. Chiong, T. Xiong, "Mid-term interval load forecasting using multioutput support vector regression with a memetic algorithm for feature selection," Energy, vol.84, pp. 419-431, 2015.

[7] C. Cecati, J. Kolbusz, P. Rozycki, P. Siano, and B. M. Wilamowski. "A Novel RBF Training Algorithm for ShortTerm Electric Load Forecasting and Comparative Studies," IEEE Trans. Ind. Electron., vol. 62, pp. 6519-6529, 2015.

[8] S. M. Barakati, S. M. R Rafiei, A. A. Gharaveisi, "Short-Term Load Forecasting Using Mixed Lazy Learning Method," Turkish Journal of Electrical Engineering and Computer Science, vol. 23, pp 201-211, 2015.

[9] K. Amber, R. Ahmad, M. Aslam, A. Kousar, M. Usman, M. Khan, "Intelligent techniques for forecasting electricity consumption of buildings," Energy, vol.157, pp. 886-893, 2018.

[10]C. Deb, F. Zhang, J. Yang, S.E. Lee, K.W. Shah, “A review on time series forecasting techniques for building energy consumption," Renewable and Sustainable Energy Reviews, vol.74, pp. 902-924, 2017.

[11]E. Yiğit, U. Özkaya, Ş. Öztürk, D. Singh, H. Gritli, "Automatic Detection of Power Quality Disturbance Using Convolutional Neural Network Structure with Gated Recurrent Unit”. Mobile Information Systems, 2021.

[12]A. Ahmad, M. Hassan, M. Abdullah, H. Rahman, F. Hussin, F, H. Abdullah, R. Saidur, "A review on applications of ANN and SVM for building electrical energy consumption forecasting," Renew. Sustain. Energy Rev, vol.33, pp.102109, 2014.

[13]S.H.A. Kaboli, A. Fallahpour, J. Selvaraj, N. Rahim, "LongTerm Electrical Energy Consumption Formulating and Forecasting via Optimized Gene Expression Programming”, Energy, vol. 126, pp 144-164, 2017.

[14]J. Runge, R. Zmeureanu, "Forecasting Energy Use in Buildings Using Artificial Neural Networks: A Review," Energies, vol.12, 2019.

[15]F. M. Ham, I. Kostanic, "Principles of Neurocomputing for Science and Engineering," New York, Mc-Graw Hill, 2001.

[16]Y. Kung, Digital Neural Networks, PTR Prentice Hall, 1998.

[17]B. Bose, "Neural Network Principles and Applications," Prentice Hall PTR, United States of America, 2002. 